\title{
Dr. Harlow Shapley
}

$\Delta \mathrm{T}$ the beginning of this year, Dr. Harlow A Shapley, director of the Harvard College Observatory and Paine professor of astronomy at Harvard since 1921, was awarded the Gold Medal of the Royal Astronomical Society for his studies of the structure and dimensions of the galactic system. On May 11 he will deliver the George Darwin Lecture of the Society, taking as his subject "Some Structural Features of the Metagalaxy".

Dr. Shapley was on the staff of Mount Wilson Observatory from 1914 until 1921 ; and during that period probably his most important contributions were t h e photometric studies relating to stellar clusters. An adaptation of the relation between the apparent brightness and the period of a Cepheid variable resulted in his determination of the now universally accepted 'period - luminosity' curve, by the aid of which great celestial distances are de. rived.

By means of this or an allied method, Dr. Shapley found the globular clusters to be at distances f r o m 20,000 to 200,000 light-years, a conclusion which revolutionised previous conceptions of the size and arrangement of the stellar universe. His many new ideas on various astronomical topics, especially variable stars, gave rise to pioneer investiga-

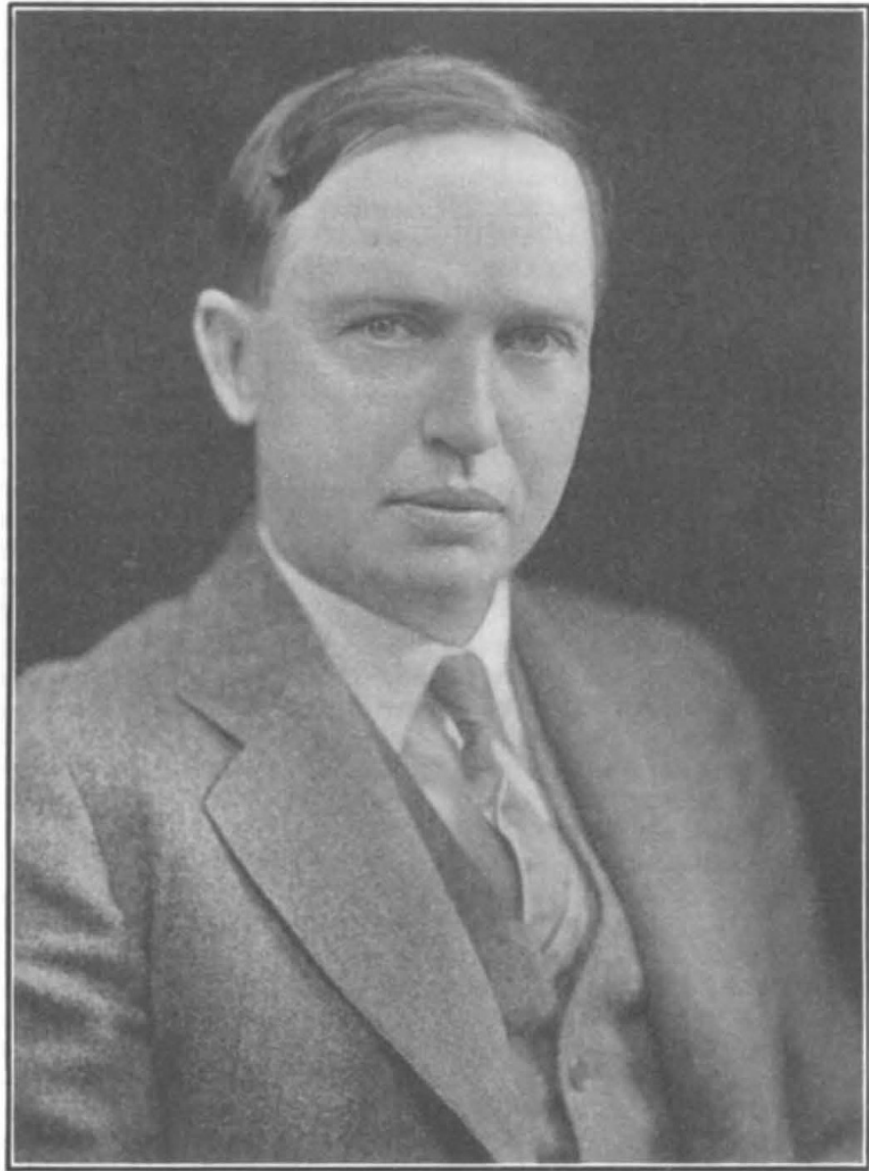

Dr. HaRlow Shapley graphed, Dr. Shapley organised, about two years ago, with the assistance of Dr. E. J. Öpik, an expert corps for the study of these objects, with observations in the clear Arizona sky and analysis at Tartu, Estonia. About 26,000 meteors were seen. An interesting first result is that only thirty per cent of the visual meteors are from the solar system, the fainter ones coming from interstellar space. Therein lies a hope of additional knowledge concerning the great ocean of space around us.

A few other sub. jects in the large observational programme at Harvard may be mentioned. The Magellanic Clouds are being studied intensively by several members of the staff, and have already yielded numerous super. giants, new peculiar spectra, clusters and variables. The programme for system. atic examination of the Milky Way in 196 selected regions has already resulted in the discovery of twenty-five hundred new variables and the determination of many periods.

The problem of the extra-galactic nebulæ is now pro. gressing steadily. The publication in 1932 of a catalogue giving the positions and photographic magnitudes of all extra-galactic nebulæ brighter than the magnitude $13 \cdot 0$, left the way clear for observational work on the second survey tions such as a study of spectral changes in Cepheids, whence came his 'pulsation theory' or 'periodic flow and ebb of heat' as the cause of such variation.

In 1921, Dr. Shapley was appointed Paine professor of astronomy at Harvard University and director of Harvard Observatory. $\mathrm{He}$ at once began to plan and carry forward a large variety of celestial explorations, extending from the casual meteor caught in the earth's atmosphere to the remotest nebulous patch on the Bruce photographs of long exposure for metagalactic surveys. His meteor project is apparently the first intensive professional attempt to study shooting stars systematically. A careful examination of about 100,000 Harvard photographs yielded a total of only 550 trails. Since many more meteors can be seen visually than are ever photo- reaching to the eighteenth magnitude and to the distance of about a hundred million light-years. The number already found on the Harvard plates exceeds one hundred thousand, and five hundred or more are often revealed by the examination of a single photograph.

The long-established practice of the Harvard Observatory in being a collector of facts has thus been continued by Dr. Shapley in many lines of research. The theoretical side is also being stressed; for example, discussions of orbits, statistical studies of star distribution, and researches upon the origin of spectral lines and on the universal abundance of elements. limited to observatory tasks. All human problems
Dr. Shapley's activities are, however, by no means 
interest him, and his versatility is illustrated by helpfulness in various educational problems, it may be counselling non-scientific faculties of several colleges as to advantageous research problems, or perchance, advising the Board of 'Trade of a 'textile' city, during the present collapse of industrial values, as to the most judicious expenditures for educational purposes.

It is not generally known that Dr. Shapley's most interesting recreation is the study of ants. For two years on Mount Wilson, he observed and studied the habits of trail-running ants, seventy thousand of them on some summer days going along each file. Under varying atmospheric conditions, he measured their speed at fixed intervals of distance. The fact was established that their speed is a function of temperature alone, and increases fifteen fold with an increase of $30^{\circ} \mathrm{C}$. in air temperature. Conversely, a single observation of the ant-speed led to the prediction of the temperature within $1^{\circ} \mathrm{C}$. Thus to his 'period-luminosity' and 'spectrum-period' relations among the stars, he added the 'speed-temperature' relation among ants. Descriptions of some of these observations will be found in the paper "Thermo. kineties of Liometopum apiculatum Mayr", published in the Proceedings of the National Academy of Sciences for April 1920. Dr. Shapley has also studied the morphology of ants, as evidenced by his large collection of worker ants with wing vestiges, described in a "Note on Pterergates in the Californian Harvester Ant" (Psyche, 27, No. 4).

Perhaps his study of ants taught Dr. Shapley not only speed, but also conservation of energy, for with all his other activities, he has found time to compile the "Source Book in Astronomy" and to write books, such as "Star Clusters", and five chapters in the "Universe of Stars", a pioneer series of radio talks given in 1925 by members of the Observatory staff. As a lecturer either at universities or before the general public, he is very successful. Why this is so may be readily understood by reading his small books "Sidereal Explorations" and "Flights from Chaos" based on lectures given at the Rice Institute of Texas, and the University of the City of New York.
A. J. C.

\section{Scientific Research in Relation to Patents in the United States*}

GINCE the War, scientists have been called $S$ upon by industry in increasing numbers for assistance in overcoming technical difficulties involving such problems as improving old products or processes, or devising entirely new products. This dependency of industry upon science has been par. ticularly marked in the chemical and electrical fields, where large industrial research laboratories have been established for investigating all phases of the products of their respective organisations. From their original task of mere laboratory control of the manufactured products, these industrial laboratories have extended their sphere of activity to such a large extent as to include research in the fundamental sciences. Industrial leaders have come to realise that fundamental research may be of vital importance to industry, for it may revolutionise existing practices or create new ones in the most unexpected quarters.

\section{Patentable Inventions other than Medicat}

These increasing contacts of scientists with the problems of industry have brought to the fore the difficult problem of adequate remuneration for their services, as well as the problem of giving the public the effective benefit of their work. In many cases valuable solutions have been made to difficulties, which were patentable. Scientists have also begun to realise that many of the fruits of their research have valuable industrial applications which can be patented. The troublesome questions thus arise: Should they proceed to obtain patents? What are the advantages in doing this ? What are the disadvantages ? A good deal of discussion has already occurred on these questions, but no definite policy has yet been formulated. The investigator who takes advantage of our patent laws is perfectly warranted in his act not only for any possible financial returns but also for the good of the public. The obtaining of some remuneration from a patent

* From "The Protection by Patents of Scientifle Discoveries", being the Report of the Committee on Patents, Copyrights and Trade Marks. Joseph Rossman (Chairman), F. G. Cottrell, A. W. Hull and A. F. Woods. Occasional Publications of the American Association for the Advancement of Science. No. 1, January, 1934. Supplement to Science, vol. 79. (New York: The Science Press.) 50 cents. is no more debasing or tainted with commercialism than the acceptance of copyright royalties from a text-book or even receiving a salary for teaching. We are at present living in an economic structure in which the making of legitimate profit is a fundamental assumption.

There are many advantages in securing patents for important advances, as only by means of patents can the legal right be secured to exclude others from practising a given process or commercialising a new product. By having such control of new discoveries the investigator is assured that his results will be used only for proper and meritorious purposes. $\mathrm{He}$ can prevent the exploitation of the public by dictating the terms under which his patent should be worked and even control the character of the commercial advertising.

\section{Medical Patents}

The committee recognises the fact that there exists in many quarters a strong feeling against medical patents. This feeling seems to be largely due to the unpleasant memories of the past exploita. tion of the public by means of 'patent medicines' which had doubtful or decidedly harmful effects on the public health. Government regulation during recent years has eliminated a great deal of misrepresentation and false claims in regard to this class of goods. The Patent Office, moreover, now seldom issues patents for the old-fashioned type of patent medicines. It is therefore an error to class all medical patents with the former types of 'patent medicines'.

The mere fact that medical patents offer the means of making profits is not a sufficient reason to con. demn them entirely. It must be remembered that patents have other very important uses. Moreover, we must bear in mind that it is possible to obtain profits from medical diserveries in many other ways without resorting tc patents if the medical investigator is so inclined. We must, after all, depend upon the integrity and cl aracter of the investigator when important medical discoveries are involved.

The ideal to strive for may perhaps be that no 